\title{
Effect of structured teaching programme on knowledge of substance abuse among adolescents
}

\author{
Das Bandana ${ }^{1}$ Bhuyan Hemeswari ${ }^{2}$ \\ Received on October 23, 2018; editorial approval December 25, 2018
}

\begin{abstract}
Introduction: Substance abuse is one of the major health challenges across the world. Adolescence is the transitional stage of physical and mental human development with substantial risk for initiating substance abuse. Objectives: To evaluate the effect of structured teaching programme on knowledge of substance abuse among adolescents. Methods: Evaluative research approach and pre-experimental one group pre-test and post- test research design was adopted for the study. One hundred twenty adolescents in the age group of 12 to 17 years studying in VII, VIII and IX were selected through proportionate stratified random sampling technique by using lottery method. Structured self-administered questionnaire was used to assess the pre-test knowledge. A structured teaching programme was prepared on substance abuse and administered followed by a post-test after seven days. Results: Out of 120 adolescents in pre-test knowledge, majority 94(78.3\%) had moderately adequate knowledge, 20(16.7\%) had inadequate knowledge and 6(5\%) had adequate knowledge. After administration of structured teaching programme during post-test only 7(5.8\%) had moderately adequate knowledge, none of them had inadequate knowledge and majority 113(94.2\%) had adequate knowledge. The mean post-test knowledge scores 22.51 was significantly higher than the mean pre-test score 11.6 as evident from ' $t$ ' value 31.054 for $d f 119$ at 0.05 level of significant. Conclusion: The structured teaching programme was effective in improving the knowledge on substance abuse among adolescents.
\end{abstract}

Keywords: Pre-experimental study, assess, self-administered questionnaire.

\section{INTRODUCTION}

Substance abuse among adolescents has become a global challenge and also an important health concern and for the past two decades there has been a dramatic increase in the demand for interventions to address the substance abuse problem. This demand has led to the development of multiple primary, secondary and tertiary substance abuse prevention programmes. ${ }^{1}$ In India, the prevalence of substance abuse which is generally low in early adolescence aged 12 and 13 rises -steeply in the late teen age and is highest during the early 20's. ${ }^{2}$ Campus atmosphere and peer pressure is forcing and influencing the adolescent students to indulge in alcoholism mainly due to lack of adequate knowledge about the consequences of its use or falsely perceived knowledge and attitude towards alcoholism as the students use alcohol for "company, festivity or curiosity". ${ }^{3}$ A study revealed that most of the young substance users started taking substances between age of 14 to 18 years and the largest member being found to be at the age of 16 and 17 years. This study further suggests that about 35 to 40 per cent of the adolescents agreed that they tried gateway substances like alcohol and tobacco. ${ }^{4}$

Time and again it has been proven that schools can provide an ideal platform for the prevention of substance abuse.
Address for correspondence:
${ }^{1}$ Clinical Instructor
Arya Nursing College
Email: bandanadas58@gmail.com
Mobile: +919706837684
${ }^{2}$ Associate Professor (Corresponding Author)
Email: hemamunukunu@gmail.com
Mobile:+918638231994
Community Health Nursing
Regional College of Nursing
Guwahati -32, Assam, India 
School can provide a supportive environment for promoting good adolescence health and they can also be extremely helpful in spreading the right message to the local community.

The objectives of this paper are to assess the pre-test knowledge of substance abuse and the effect of structured teaching programme on knowledge of substance abuse among adolescents.

\section{MATERIALS AND METHODS}

Study Design: Experimental design, to assess the effect of structured teaching programme on knowledge of substance abuse among adolescents.

\section{Sampling technique: Purposive sampling}

Study population: Selected High Schools of Kamrup Metro, Assam, viz., Maligaon High School, Maligaon and Tetelia High School, Gotanagar. Students of class VII, VIII and IX by using proportionate stratified random sampling technique with lottery method.

Data collection tools and techniques: A pretested and predesigned questionnaire was used to assess the knowledge of substance abuse among adolescents.

\section{Study variables}

Demographic variables consisted of age, education, gender, types of family, monthly income of the family, occupation of the father and occupation of the mother, no. of siblings, birth order, family history of substance use and availability of easy sources of substance.

Variables in relation to questionnaire to assess the knowledge of adolescents before and after administering structured teaching programme regarding substance abuse. In the final draft the questionnaire consists of 25 items.

Each question has only one correct answer. For each correct answer score 'one' (1) was given and for wrong answer 'zero' (0) was given. The maximum score was 25 .

The reliability of the tools was done by Cronbach's alpha method. Findings of the study revealed that the tool was found to be reliable. The reliability of knowledge was 0.86 . Before starting the final data collection procedure for the present study; the investigator obtained permission from the institutional ethical research committee of Regional College of Nursing, Guwahati, Assam. Permission was obtained from authorities of selected High schools of Kamrup, Metro, Assam. The data collection period was scheduled from 24th January 2017 to 2nd March 2017. The purpose and importance of the study was explained by the investigator to the adolescents prior to data collection and keeping in mind the ethical aspect of research. Data was collected after obtaining informed

Table 1 Level of knowledge based on scores regarding substance abuse

\begin{tabular}{|l|l|}
\hline Level of knowledge & Score range \\
\hline Adequate (Mean + SD) & Above 15 \\
\hline Moderate (Mean -SD to Mean + SD) & 8 to 15 \\
\hline Inadequate (Mean - SD) & Below 8 \\
\hline
\end{tabular}

consent of the adolescents for their willingness to participate in the study. A pre-test was conducted to the selected adolescents for 30 minutes with structured self-administered questionnaire. After the pre-test, a structured teaching programme on substance abuse of 45 minutes was implemented on the same day. All the study subjects were informed regarding the post-test which was scheduled exactly after one week of the implementation of the structured teaching programme. The data analysis was consisted of descriptive and inferential statistics.

\section{RESULTS}

The data were grouped and analysed under following sections:

a) Frequency and percentage distribution of adolescents according to demographic characteristics

Out of 120 respondents, equal number of respondents i.e., $60(50 \%)$ were from each age group 12-14 and $15-17$ years. Majority of the respondents 53(44.1\%) were from class IXth standard. 61(50.8\%) were male respondents. The highest percentage of respondents 63(52.5\%) were belongs to nuclear family. Majority of the respondents $31(25.8 \%)$ had monthly family income Rs. 6, 851 -Rs 17,150. Maximum no. of $66(55 \%)$ of the respondents' father and $47(39.2 \%)$ of mothers had occupation as business. Highest percentage of respondents $48(40 \%)$ had two siblings. $48(40 \%)$ of respondents had birth order second. Maximum 66(55\%) of the respondents had no family history of substance use. Majority of the respondents $83(69.2 \%)$ were agreed availability of easy sources of substance within 100 meters radius of the school.

b) Assessment of pre-test knowledge of adolescents regarding substance abuse $n=120$

Figure 1 depicts that out of 120 respondents in pre-test, majority $94(78.3 \%)$ of the respondents had moderately adequate knowledge on substance abuse, $20(16.7 \%)$ had inadequate knowledge and only $6(5 \%)$ had adequate knowledge. Thus, the finding indicates that there is lack of knowledge regarding substance abuse among adolescents.

c) Effect of structured teaching programme on substance abuse

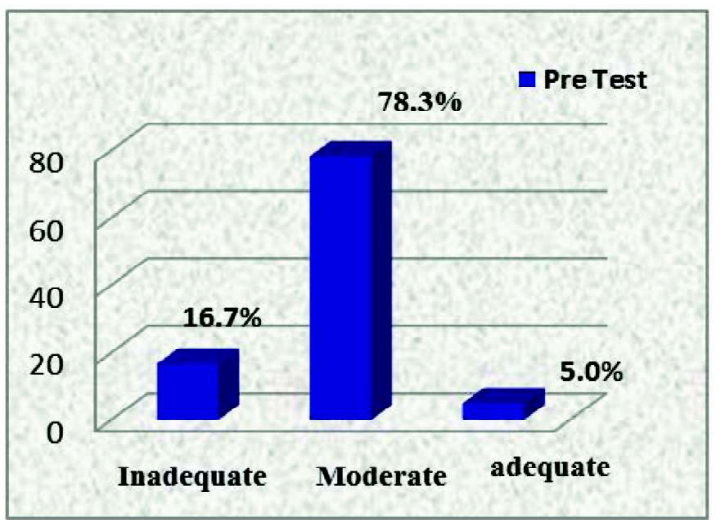

Figure 1 Respondents in terms of pre-test knowledge scores on substance abuse 
The data presented in Table 1 shows that in the pre test of respondents $94(78.3 \%)$ have moderately adequate knowledge, 20(16.7\%) have inadequate knowledge and only $6(5.0 \%)$ have adequate knowledge whereas in the post test, only $7(5.8 \%)$ had moderately adequate knowledge, none of respondents had inadequate knowledge and majority 113(94.2\%) had adequate knowledge on substance abuse.

Table 1 Pre-test and post test knowledge scores in terms of frequency and percentage $(n=120)$

\begin{tabular}{|c|c|c|c|c|c|}
\hline Level of knowledge & Score range & \multicolumn{2}{|c|}{ Pre-test } & \multicolumn{2}{|c|}{ Post-test } \\
\hline Inadequate & $<8$ & 20 & 16.7 & $\ldots$ & \\
\hline Moderate & $8-15$ & 94 & 78.3 & 7 & 5.8 \\
\hline Adequate & $>15$ & 6 & 5.0 & 113 & 94.2 \\
\hline Total & & 120 & 100 & 120 & 100 \\
\hline
\end{tabular}

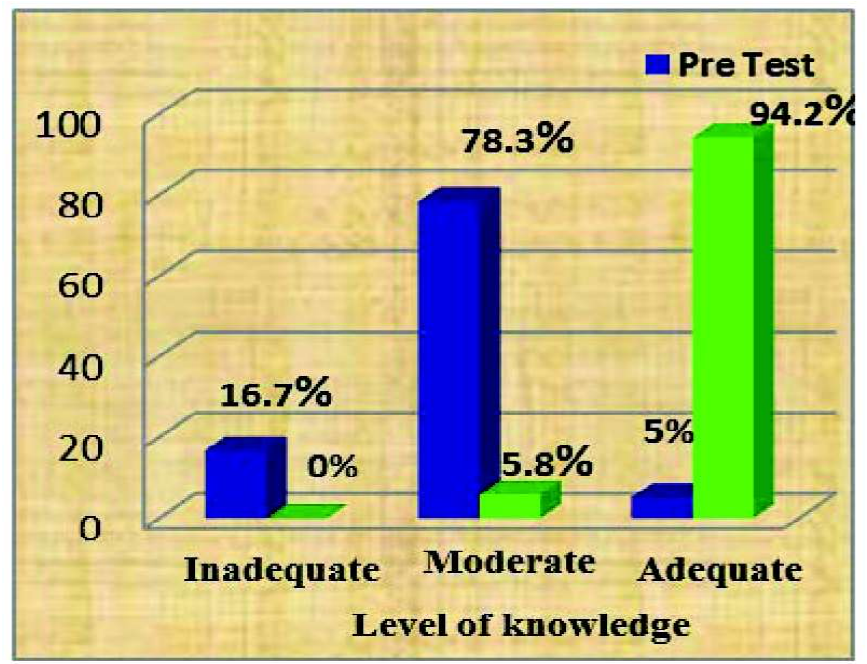

Figure 2 Comparison of pre-test and post-test knowledge score on substance abuse

Table 2 Paired ' $t$ ' test between pre-test and post-test knowledge scores on substance abuse $(\mathrm{n}=120)$

\begin{tabular}{|l|l|l|l|l|l|l|}
\hline Knowledge & Mean & $\begin{array}{l}\text { Std. } \\
\text { Dev }\end{array}$ & df & 't' & p value & Remarks \\
\hline Pre & 11.6 & 3.22 & 119 & 31.054 & 0.000 & $\mathrm{~S}^{* *}$ \\
\hline Post & 22.51 & 2.46 & & & & \\
\hline
\end{tabular}

The data presented in Table 2 shows that the mean post test knowledge scores (22.51) is significantly higher than the mean pre-test score (11.6) as evident from 't' value 31.054 for $\mathrm{df}$ 119 at 0.05 level of significant. Hence, the scores of post test $(\mathrm{SD} \pm 2.46)$ is less dispersed than the score of pre-tests $(\mathrm{SD} \pm 3.22)$.

Therefore, it can be interpreted that the knowledge of adolescents on substance abuse has been increased significantly in the post test and that the structured teaching programme is highly effective.

d) Association of pre-test knowledge with selected demographic variables

The study shows that there was no significant association between pre-test knowledge and selected demographic variables such as age, education, gender, types of family, occupation of the father, occupation of mother, number of siblings, birth order and availability of easy sources of substance. It is therefore concluded that pre-test knowledge is independent from the above parameters. In other words; these factors can't influence on the findings of the present study. However, significant p-value, i.e., $(<0.05)$ witnessed in case of family history of substance use reveal that there is certain link of this factor with the pre-test knowledge.

\section{DISCUSSION}

The present study reveals majority $94(78.3 \%)$ of the adolescents had moderately adequate knowledge on substance abuse. The present study was in accordance with study conducted by Ganakshi D, Sakun S, Poudel S (2014). ${ }^{5}$

On evaluating the effect of structured teaching programme on knowledge of substance abuse among adolescents showed that the adolescents had lack of knowledge regarding substance abuse. This study was found to be similar with results of Tuppad B S (2014). ${ }^{6}$

Association between pre-test knowledge on substance abuse with selected demographic variables reveals no significant association between pre-test knowledge score and selected demographic variables except the family history of substance abuse. The study was supported by the study of Benitto JA. ${ }^{?}$

\section{CONCLUSION}

The study was conducted to find out the effect of structured teaching programme on substance abuse among adolescents. The finding of the study showed that in the pre-test, majority $78.3 \%$ of the adolescent had moderately adequate knowledge, $16.7 \%$ had inadequate knowledge and only $5 \%$ had adequate knowledge regarding substance abuse. After administration of structured teaching programme, in post-test only $5.8 \%$ had moderately adequate knowledge, none of them inadequate knowledge and majority $94.2 \%$ had adequate knowledge regarding substance abuse. The mean post-test knowledge scores 22.51 was significantly higher than the mean pre test score 11.6 as evident from ' $t$ ' value 31.054 for df 119 at 
0.05 level of significant. So the findings reveals that the knowledge of adolescents on substance abuse increased significantly in the post test. There was no significant association found between pre-test knowledge scores and selected demographic variables except family history of substance use. On the basis of the findings of the study, it can be concluded that the structured teaching programme is effective in improving the knowledge of adolescents regarding substance abuse.

Acknowledgement: We extend our heartfelt thanks to all the teaching and office staff of Regional College of Nursing for their valuable help and support during the entire period of this project. Our special thanks goes to all the participants without whose help and cooperation could not have been completed the study.

\section{Conflict of interest: None.}

Ethical clearance: Taken.

Source of finding: None declared.

Author declaration: We declare that this work is done by the authors named in this article and all liabilities pertaining to the claim relating to the content of this article will be borne by the authors.

\section{REFERENCES}

1. Sharma RR. Knowledge of psychoactive substance use: disorders among college students. Nursing journal of India 2001;92(2):29-30.

2. Gulani KK. Community Health Nursing. $1^{\text {st }}$ ed. New Delhi: Kumar publication; 2006. p. 29 -35.

3. Ponnudurai. Alcohol \& drug abuse among college students. Indian Journal of Psychiatry 1984;26(2):12832.

4. Panda S, Sharma M. Needle syringe acquisition and HIV prevention among injecting drug users: A treatise on the "good and not good" public health practices in South Asia. J of substance use and misuse 2016;41(6):953-77.

5. Ganakshi D, Singh S, Paudel S. Knowledge and attitude on ill-effects of smoking among adults residing in Lekhnath, Kashi, Nepal. Ind $\mathbf{J}$ of community health 2014;26(3):308-10.

6. Tuppad BS. A study to evaluate the effectiveness of STP on knowledge regarding ill-effects of smoking among students of Government High School, Bangalore. $\mathrm{J}$ of psychiatric nursing 2014;25(3):11-25.

7. Benitto JA. Effectiveness of video-assisted teaching module on effects of substance abuse on health and its preventive measures among adolescents. J of psychiatric nursing 2013;2(1):1-36. 